\title{
Virtual child pornography as potential remedy against child sexual abuse
}

\author{
Laure van Es \\ Maastricht University \\ Lae.vanes@student.maastrichtuniversity.nl
}

\begin{abstract}
This study focusses on the potential effects of virtual child pornography on the sexual abuse of children, which is a widespread problem. Recent news items about child sexual abusers have brought the issue of pedophilia into the public eye. The media uses these two terms interchangeably. However, there is an essential difference between pedosexuals (those who sexually abuse children) and pedophiles (those who are sexually attracted to children). It is important to notice that not all pedophiles abuse children and not all pedosexuals feel sexually attracted to children. The research question is if virtual child pornography can prevent pedophiles from converting their fantasies into sexual acts. Literature retrieved by a search using PubMed. Sixty-four articles dealing with child sexual abuse, pedophilia, possible treatments for pedophilia and the effects of (virtual) child pornography were analyzed. Furthermore, information on treatment in the Netherlands was requested from the Hotline Child Pornography and an interview was arranged with Jules Mulder, therapist of pedosexuals and pedophiles at forensic psychiatric center De Waag in Utrecht, The Netherlands.
\end{abstract}

Pedophilia is manifested mostly in downloading child pornography. The amount of child pornographic material available has increased dramatically. Earlier research on the characteristics of child pornography downloaders showed that there is great diversity among them; pedophiles are present in all layers of society. Despite that not all pedophiles act on their feelings there is still an elevated risk of abusing young children sexually. Therefore, preventive treatment is very important. Unfortunately, there is limited research performed on treatment for pedophilia. Experts suggest that impulse control is the highest achievable and pedophilia cannot be cured. Child pornography can be used for impulse control. Research performed in various countries showed that when downloading child pornography was allowed, the number of sexually abused children decreased. Child 
pornography can provide pedophiles in their sexual needs and may prevent that they will abuse young children in the future. However, the provision of child pornography as part of a treatment gives rise to an ethical dilemma, because it indirectly maintains sexual child abuse. Therefore virtual child pornography could be a solution. Further research is needed on the effects of virtual child pornography, taking into account the heterogeneity among pedophiles.

\section{Keywords}

Pedophilia, child sexual abuse, treatment, virtual child pornography

\section{Introduction}

Child sexual abuse is a widespread problem and has many negative consequences for a child (Barth, Bermetz, Heim, Trelle, \& Tonia, 2013). Recent news items about child sexual abusers have brought the issue of pedophilia into the public eye. Nowadays, there is little tolerance for pedophiles, unlike in the 705 and early 80 . Headlines are filled with news about 'sexual abusers' defined as 'convicted pedophiles'. The media uses these two terms interchangeably. However, there is an essential difference between pedophiles, who feel sexually attracted to young children, and pedosexualswho abuse young children; they act due their sexual fantasies. It is important to notice that not all pedophiles abuse children and not all pedosexuals feel sexually attracted to children.

Despite the fact that not all pedophiles act on their sexual feelings, there is still an elevated risk of abusing young children sexually (Babchishin, Hanson, Hermann, 2011). Therefore, it is very important to give a look at the different treatment options, because treatment is more effective than imprisonment (Schönberger \& Kogel, 2012). Unfortunately, there is limited research done on treatment for pedophilia specific. Experts suggest that impulse control is the highest achievable and pedophilia cannot be cured. Pornography can be used for impulse control. It is known that pornography is a protective factor against sexual violence (Ferguson \& Hartley, 2009; Landripet, Stulhofer \& Diamond, 2006; Diamond, 2009). It may be possible that child pornography can satisfy pedophiles in their sexual needs. In this way, child pornography can prevent pedophiles to abuse young children sexually. However, the provision of child pornography as part of a treatment is unethical, since it indirectly maintains sexual child abuse. Therefore virtual child pornography could be a solution. 


\section{Material and methods}

The objective of this research was to gain insight into the potential contribution of virtual child pornography in preventing pedophiles to act due their sexual fantasies. The research question is if virtual child pornography can prevent that pedophiles convert their sexual fantasies into sexual acts. To answer the research question, a literature review was done. PubMed and reference lists of other articles were used to search for relevant literature. Via PubMEd was searched on the keywords: pedophilia, pedophiles, child sexual abuse, sexual offenders, treatment, child pornography and virtual child pornography. In total, 64 articles were selected for this review based on the relevance of the abstract. To get more information about the treatment for pedophiles in the Netherlands, Stop It Now! has been contacted. Stop It Now! is a helpline for pedophiles and their environment. Via Stop It Now! an interview was arranged with Jules Mulder, therapist of pedosexuals and pedophiles in forensic psychiatric center De Waag in Utrecht, The Netherlands.

\section{Results}

The DSM-IV-TR does not distinguish between pedosexuality and pedophilia; there is one classification for both, namely "pedophilia". Pedophilia is subsumed under "paraphilias", which belongs to sexual dysfunctions. In the DSM-5, which was introduced in 2013, efforts have been made to distinguish between pedophilia and pedosexuality. Here belongs pedophilia to “Pedohebephilic Disorder” (American Psychiatric Association, 2013).

How often pedophilia and pedophile disorders occurs is hard to say - facts and figures are unknown. However, we do know that sexual abuse of children is a very common problem. Worldwide, the estimates of prevalence of child sexual abuse vary from 8-31\% for girls and 3-17\% for boys (Barth et al., 2013). In the past, research has been done into sexual interest in young children among male students (Briere \& Runtz, 1989, Templeton \& Stinnett, 1991; Bagley, Wood, \& Young, 1994). Self-reported questionnaires shows that 5-9\% of young men (18-27 years) have sexual fantasies about young children (under 13 years). The sexual interest in children can vary from attraction, fantasies, masturbation and the likelihood to sexual abuse young children.

Pedophilia mostly expresses itself in downloading child pornography. Riegel (2004) concluded that $95 \%$ out of 290 self-identified pedophiles at least watched child pornography occasionally. The amount of child pornographic material available has increased dramatically and an increasing number of people are caught for having child pornography on their computers. This is probably only a small percentage of all child 
pornography downloaders, since most child pornography is distributed by the invisible part of the internet and via peer-to-peer networks (Temporini, 2012). Research on the characteristics of child pornography downloaders shows that there is great diversity among them; they are found in all layers of society. Most of them are Caucasian males (Van Wijk , Nieuwenhuis, \& Smeltink, 2009; Seto \& Eke, 2005; Van der Zee \& Groeneveld, 2007), however this could be misleading since the most research is done in the Western world. Downloaders occur at any age between 19 and 76 years (Seto \& Eke, 2005). The largest group downloaders aged between 25 and 45 years (Van Wijk et al., 2009; Hulst \& Neve, 2008). As well single and married men occur among downloaders; and some of them even have children themselves (Henry, Mandeville-Norden, Hayes, \& Egan, 2010; Reijnen, Bulten, \& Nijman, 2009). According to Van der Hulst and Neve (2008) downloaders occur in all professional and educational levels. Downloaders tend to have above-average intelligence level and more than 30\% of them are highly qualified. (McCarthy, 2010; Seto, Cantor, \& Blanchard, 2006). They also often appear to have a good job as a lawyer, doctor and school director (Sea \& Groeneveld, 2007). However, jobs with little social interaction, such as in the ICT sector, are common among downloaders of child pornography (Sullivan, 2005). Psychosocial problems and socio-affective deficits are relatively common, which may affect treatment (McCarthy, 2010).

\section{Treatment}

Previously, pedophiles were treated by the conditioning principle. This treatment is based on linking an aversive (unpleasant) stimulus with stimuli that are related to a person's sexual preference (Camilleri \& Quinsey, 2008). This would result in a reduction in measured sexual arousal for children (Quinsey, Bergersen \& Steinman, 1976; Quinsey, Chaplin \& Carrigan, 1980). However, subsequent studies demonstrate no long-term effect(Laws, 2001, Quinsey \& Earls, 1990). Since the 80's, treatment for pedophiles and pedosexuals is more focused on criminal behavior (hands-on offences) and less on the underlying psychiatric problems. There is more emphasis on the risk factors that sustain criminal behavior (Meijer, Pomp, \& Pantus, 2009). The effectiveness of treatments is mainly determined by the recidivism rate; how many offenders once again abuse children after completing the treatment. The treatment which is regarded as most effective today is cognitive-behavioral treatment (CBT). It focusses on criminogenic psychological factors, such as deviant sexual interests, cognitive distortions, an impulsive lifestyle and a higher tolerance for sexual abuse (Meijer et al., 2009). In addition, during treatment there is also a lot of attention for relapse prevention and increasing the social competences. However, it is still unclear whether these interventions also will be effective in the treatment of pedophiles, who did not commit any hands-on crime yet. 
Treatment for pedophiles in the Netherlands is limited. There is a helpline for pedophiles, called Stop It Now!, which can be contacted anonymously. The aim of Stop It Now! is to prevent and stop child sexual abuse. Stop It Now! also informs pedophiles about the treatment at De Waag, an outpatient forensic psychiatric center in the Netherlands. The treatment for pedophiles at De Waag is focused on making life bearable for pedophiles and prevent that they will sexual abuse young children in the future, by using CBT and social skills-enhancing techniques. However, pedophilia cannot be cured; impulse control is the highest achievable. Therefore, treatment at De Waag is palliative. This means that the treatment is purely focused on keeping life bearable for the patient.

\section{Pornography}

The most common definition of pornography is the one of Hald and Malamuth. They describe pornography as "any kind of material aiming at creating or enhancing sexual feelings or thoughts in the recipient and, at the same time, containing explicit exposure and/or descriptions of the genitals and clear explicit sexual acts." (Hald \& Malamuth, 2008). In general, pornography is seen as something positives. Watson and Smith (2012) concluded that the use of pornography leads to an increase of satisfaction, and may decrease anxiety and sexual dysfunction. There also appears to be a link between pornography and sexual violence. Recent studies show that there is a negative correlation between pornographic material and sexual abuse (Ferguson \& Hartley, 2009; Landripet et al., 2006; Diamond, 2009).

While pornography is generally valued positively, for child pornography this is not the case. A lot of people believe that child pornography contributes to the development of sexual interest in children and thereby could be associated with a higher incidence of child sexual abuse. However research shows that this is not the case. Moreover, child pornography seems to be a protective factor, according to Diamond, Jozifkova and Weis (2010). They examined the number of sexual offenses that took place in Czechoslovakia from the 70's till the end of 2007. At the end of 1989 the velvet revolution took place; the Czech Republic became a democracy and the prohibition of pornography was lifted. During the next 17 years child pornography was accepted. Initially one would expect that the number of sexually abused children would increase, but Diamond and his colleagues concluded the opposite. During the same 17 years, they found a decrease in the number of cases of sexual abused children. Also in Japan and Denmark child sexual abuse decreased in the period when child pornography was not prohibited (Kutchinsky, 1973; Diamond \& Uchiyama, 1999). 


\section{Discussion/Conclusion}

A literature review was done to investigate whether virtual child pornography could contribute in treating pedophiles to prevent that they will sexual abuse children in the future. To answer this question the difference between pedosexuals and pedophiles, the demographic characteristics of pedophiles and how often pedophilia occurs were described. In addition, several sources have been consulted about the treatment of pedophiles, the effectiveness of this treatment and which treatment is provided in the Netherlands. The effect of (child) pornography is discussed on sexuality and aggressiveness. Finally, the possibility of child pornography during treatment has been considered.

Research shows that an increase in child pornography leads to a decrease of sexual abuse. A possible explanation for the fact that child pornography leads to a decrease of child sexual abuse could be that it serves as a replacement for the sexual act. Child pornography may provide pedophiles in their sexual needs, without them having to act to their sexual feelings. This indicates that child pornography could be applied during treatment for pedophiles, to prevent that they will proceed to physical sexual abuse. Nevertheless, legalizing real child pornography is not a suitable solution. For the production of real child pornography are children actually sexual abused. Hereby, it indirectly maintains sexual abuse of children. It is unethical to allow sexual abusing of some children to protect (many) other children. Therefore, virtual child pornography could be a solution. Virtual child pornography could serve the same function as real child pornography, but without the actual abuse of children. If virtual child pornography has the same effect as real child pornography is still unclear. There is a possibility that pedophiles feel not the same by watching virtual child pornography as by real child pornography, even though it looks almost the same. Therefore further research is necessary. Unfortunately, virtual child pornography is also prohibited in the Netherlands since 2002; which makes it impossible to do further research in the Netherlands. In case a legislative amendment makes further research possible in the future, it must be properly investigated if virtual child pornography also has a protective effect and whether this applies to all pedophiles. For instance, virtual child pornography can cause a general decline in sexual child abuse, but the possibility still remains that in some cases it could lead to practicing behavior. Therefore, it is highly recommended to find out for which pedophiles virtual child pornography should be made available during treatment in the future and for whom not. 


\section{Role of the student}

Laure van Es was an undergraduate student working under the supervision of Marieke Dewitte. The topic was proposed by the supervisor and Laure van Es. The literature review, the processing of the results as well formulation of the conclusions and the writing were done by the student.

\section{References}

1. American Psychiatric Association. (2013). Diagnostic and statistical manual of mental disorders (5th ed.). Washington, DC: Author.

2. Babchishin, K.M., Hanson, R. K., \& Hermann, C. A. (2011). The characteristics of online sex offenders: a meta-analysis. Sexual Abuse, 23(1), 92-123

3. Bagley, C., Wood, M., \& Young, L. (1994). Victim to abuser: Mental health and behavioral sequels of child sexual abuse in a community survey of young adult males. Child Abuse \& Neglect, 18(8), 683-697.

4. Barth, J., Bermetz, L., Heim, E., Trelle, S., \& Tonia, T. (2013). The current prevalence of child sexual abuse worldwide: a systematic review and meta-analysis. International Journal of Public Health, 58(3), 469-483.

5. Beek, E. van. (2012). Achilleshiel van Nederland: de pedofiel uitgedaagd. Tijdschrift voor Seksuologie, 36(3), $191-196$

6. Briere, J., \& Runtz, M. (1989). University males' sexual interest in children: Predicting potential indices of “pedophilia” in a nonforensic sample. Child Abuse \& Neglec,. 13(1), 65-75.

7. Camilleri, J. A., \& Quinsey, V. L., (2008). Pedophilia, Assessment and Treatment. In D. R. Laws \& W. T. O’Donohue (Eds.), Sexual deviance: Theory, assessment and treatment. New York: Guilford.

8. Diamond, M. \& Uchiyama, A. (1999). Pornography, rape and sex crimes in Japan. International Journal of Law and Psychiatry, 22(1), 1-22.

9. Diamond, M. (2009). Pornography, public acceptance and sex related crime: a review. International Journal of Law and Psychiatry, 32(5), 304-314.

10. Diamond, M., Jozifkova, E., \& Weiss, P. (2011). Pornography and sex crimes in the Czech Republic. Archives of Sexual Behavior, 40, 1037-1043.

11. Ferguson, C. J., \& Hartley, R. D. (2009). The pleasure is momentary...the expense damnable? The influence of pornography on rape and sexual assault. Aggression And Violent Behavior, 14(5), 323-329.

12. Hald, G. M., \& Malamuth, N. M. (2008). Self-perceived effects of pornography consumption. Archives of Sexual Behavior, 37, 614-25

13. Henry, O., Mandeville-Norden, R., Hayes, E., \& Egan, V. (2010). Do internet-based sexual offenders reduce to normal, inadequate and deviant groups? Journal of Sexual Aggression, 16(1), 33-46.

14. Hulst, van der, R.C. \&. Neve R.J.M. (2008). High-tech crime, soorten criminaliteit en hun daders. Een literatuurinventarisatie. Den Haag: WODC / Boom Juridische Uitgevers. Nr. 264.

15. Kutchinsky, B. (1973). The effect of easy availability of pornography on the incidence of sex crimes: the Danish experience. Journal of Social Issues, 29, 163-181. 
16. Landripet, I., Stulhofer, A., \& Diamond, M. (2007). Assessing the influence of pornography on sexual violence: a cross-cultural perspective. In: International Academy for Sex Research conference. Amsterdam, The Netherlands (July 12-15).

17. Laws, D. R. (2001). Olfactory aversion: Notes on procedure, with speculations on its mechanism of effect. Sexual Abuse: A Journal of Research and Treatment, 13(4), 275-287

18. McCarthy, J. A. (2010). Internet sexual activity: A comparison between contact and noncontact child pornography offenders. Journal of Sexual Aggression, 16(2), 181-195.

19. Meijer, W. A., Pomp, E. R., \& Pantus, M. J. G. (2009). De effectiviteit van behandeling bij pedoseksuelen: bevingen van een meta-analyse. Actuele kennis 13, EFP Utrecht.

20. Quinsey, V. L., \& Earls, C. M. (1990). The modification of sexual preferences. In W.L. Marshall, D. R. Laws, \& H. E. Barbaree (Eds.), Handbook of sexual assault: Issues, theories, and treatment of the offender (pp. 279295). New York, Plenum Press.

21. Quinsey, V. L., Bergersen, S. G., \& Steinman, C. M. (1976). Changes in physiological and verbal responses of child molesters during aversion therapy. Canadian Journal of Behavioural Science, 8, 202-212.

22. Quinsey, V. L., Chaplin, T. C., \& Carrigan, W. F. (1980). Biofeedback and signaled punishment in the modification of inappropriate sexual age preferences. Behavior Therapy, 11(4), 567-576.

23. Reijnen, L., Bulten, E., \& Nijman, H. (2009). Demographic and Personality Characteristics of Internet Child Pornography Downloaders in Comparison to Other Offenders. Journal of Child Sexual Abuse, 18(6), 611-622.

24. Riegel, D. L. (2004). Effects on boy-attracted pedosexual males of viewing boy erotica. Archives of Sexual Behavior, 33(4), 321-323.

25. Schönberger, H. J. M., \& Kogel, C. H. (2012). Kenmerken en recidivecijfers van ex-terbeschikkinggestelden met een zedendelict. Memorandum, 1, 1-58.

26. Seto, M. C., \& Eke, A. W. (2005). The criminal histories and later offending of child pornography offenders. Sexual abuse: A Journal of Research and Treatment, 17(2), 201-210.

27. Seto, M. C., Cantor, J. M., \& Blanchard, R. (2006). Child pornography offenses are a valid diagnostic indicator of pedophilia. Journal of Abnormal Psychology, 115(3), 610.

28. Sullivan, C. (2005). Internet traders of child pornography: profiling research. Wellington: New Zealand Censorship Compliance Unit.

29. Templeton, T. L., \& Stinnett, R. D. (1991). Patterns of sexual arousal and history in a normal sample of young men. Archives of Sexual Behavior, 20(2), 137-150

30. Temporini, H. (2012). Child pornography and the internet. Forensic Psychiatry, 35(4). 821-835.

31. Watson, M. A., \& Smith, R. D. (2012). Positive porn: educational, medical, and clinical uses. American Journal of Sexuality Education, 7, 122-45

32. Wijk, A. van, Nieuwenhuis, A., \& Smeltink, A. (2009). Achter de schermen. Een verkennend onderzoek naar downloaders van kinderporno. Arnhem, Bureau Bekereeks.

33. Zee, S. van der, \& Groeneveld, C. (2007). Kinderpornografisch beeldmateriaal. In: Wijk, van A. Ph., Bullens, R.A.R. \& Eshof, van den, P. (Eds). Facetten van zedencriminaliteit. (pp 229-246). 's-Gravenhage: Reed Business Information bv. 